\title{
Psychiatric morbidity in patients with peripheral vestibular disorder: a clinical and neuro-otological study
}

\author{
S Eagger, L M Luxon, R A Davies, A Coelho, M A Ron
}

\begin{abstract}
This study reports the psychiatric morbidity in 54 patients with objective evidence of peripheral vestibular disorder seen three to five years after their original referral. A third of the patients were free from vestibular symptoms at follow up and $a$ further third had experienced some improvement. Two thirds of the patients had experienced psychiatric symptoms during this period, although only $50 \%$ were rated above the cut off point for significant psychiatric disturbance when interviewed. Panic disorder with or without agoraphobia and major depression were the commonest psychiatric diagnoses. Patients with classical "labyrinthine" symptoms had a more severe canal paresis than the rest, but the degree of the abnormalities in the neuro-otological tests was unrelated to outcome or to psychiatric morbidity. On the other hand, there was a significant correlation between the presence of vestibular symptoms and psychiatric morbidity, which in turn correlated with measures of anxiety, perceived stress and previous psychiatric illness.
\end{abstract}

Dysequilibrium is a common and disabling symptom often associated with psychiatric morbidity. Panic attacks and other anxiety disorders ${ }^{12}$ have been described in association with peripheral vestibular disease. More specific syndromes such as "space" phobia ${ }^{3}$ and "motorist's disorientation syndrome" have also been described in patients with peripheral or central vestibular abnormalities. Despite the awareness of this link between vestibular dysfunction and psychopathology, no systematic studies have been conducted in patients with objective evidence of peripheral vestibular pathology aimed at documenting the type and frequency of psychiatric morbidity.

Conversely, complaints of dizziness and feelings of loss of balance are extremely common in psychiatric patients, especially those with panic and other anxiety disorders such as agoraphobia. Vestibular abnormalities have also been documented in these patients ${ }^{5-7}$ and it seems likely that in some vestibular dysfunction may play an important role in the aetiology of the symptoms. However the small numbers of patients included in these studies, the confounding effects of psychotropic medication and the choice of tests of vestibular function make it difficult to interpret their results.

We report the psychiatric morbidity encountered in a group of patients selected for the presence of identifiable peripheral vestibular pathology who were seen three to five years after their initial referral and who were not taking psychotropic drugs when tested at follow up.

\section{Methods}

SUBJECTS

The clinical notes of all the patients referred to the Neuro-otology Department of the National Hospital for Neurology and Neurosurgery during 1984 and 1985 with an episode of dysequilibrium as defined by complaints of vertigo, dizziness, unsteadiness, giddiness or lightheadedness were scrutinised. Those in whom there was objective evidence of peripheral vestibular pathology at the time of their first attendance were selected for the study. This decision was made by one of us (LML) based on: a) Unilateral canal paresis on standard Fitzgerald-Hallpike caloric testing ${ }^{8}$ in the absence of optic fixation, of greater than $8 \%$ based on the Jongkees formula ${ }^{9}$ using duration criteria, and/or; b) First degree uni-directional spontaneous nystagmus with slow component velocity greater than five degrees per second demonstrated by direct current electronystagmography (ENG) recording across both eyes.

The presence of a directional preponderance, a common associate of peripheral vestibular dysfunction which reflects asymmetry within the two halves of the vestibular system, was not an inclusion criterion, but its presence was noted if greater than $8 \%$, based on the Jongkees formula ${ }^{9}$ using duration criteria on standard Fitzgerald-Hallpike caloric testing.

Patients were excluded if there was evidence of Meniére's syndrome or central vestibular disorder, if they had other neurological or systemic illness or had sustained head injuries with loss of consciousness. One hundred and two patients fulfilled the inclusion criteria.

A brief questionnaire was sent to all patients enquiring about psychiatric symptoms and dysequilibrium during the follow up period. Nine patients could not be traced or failed to reply. Of the $93(91 \%)$ who did, 69 were willing to attend the hospital for further tests. The heavy clinical load of the department allowed us to test only the first 54 (26 males, 28 females) who replied to our enquiry. Twenty four were unavailable or unwilling to attend for a variety of reasons (for example, distance, 
work, family commitments), but none cited a reason related to their vestibular disorder.

\section{PSYCHIATRIC ASSESSMENT}

The mental state at the time of interview was assessed by one of us (SE) (unaware of the current neuro-otological status) using the following instruments:

1) The Clinical Interview Schedule (CIS), ${ }^{10}$ aimed at detecting neurotic symptoms, includes subjective and observer ratings. A cut off point of 14 or over (range 0-30) for significant psychiatric morbidity was used. The total score and the individual symptom ratings were used in the analysis.

2) Beck Depression Inventory (BDI). ${ }^{11}$

3) The Social Stress and Support Interview Schedule $(S S S I)^{12}$ explores the degree of stress and support, experienced by the patient, in the areas of work, finances, housing, social, marital and family circumstances. Stress in each of these areas was rated $(+1=$ support experienced, 0 neither support nor stress and $-1=$ stress experienced) and a total score was obtained adding the partial scores.

4) The Fear Questionnaire, ${ }^{13}$ a self-rating scale, comprises three subsections exploring symptoms of agoraphobia, social phobia and blood/ injury phobia. Each of the three subsections has 5 items, each rated from 0 (no avoidance) to 8 (total avoidance). Fears of falling, heights, the dark and any other phobias were rated using the same method.

5) The State-Trait Anxiety Inventory, ${ }^{14}$ a self reported measure of subjective anxiety, comprises two 20-item scales: the A-"state" scale requires subjects to report current feelings of anxiety and the A-"trait" scale long standing, background symptoms.

Information was obtained about psychiatric symptoms experienced before and since the onset of the vestibular disturbance, impact of disability in everyday life, previous physical health and family history of mental illness.

NEURO-OTOLOGICAL ASSESSMENT

To ascertain whether certain vestibular symptoms were more likely to be associated with the presence of psychiatric morbidity, patients were divided into two groups according to the presenting complaints. The "labyrinthine" group had experienced discrete episodes of acute rotational vertigo, associated with nausea and vomiting with gradual improvement over a few weeks or had the characteristic history and clinical signs of benign positional vertigo of paroxysmal type. The rest had experienced vague symptoms of dysequilibrium such as unsteadiness, lightheadedness or giddiness. Eighteen (33\%) of the 54 patients examined at follow up belonged to the labyrinthine group, while this was the case for $10(26 \%)$ of the remaining 39 cases not seen at follow up.

The frequency of the episodes of dysequilibrium experienced during the follow up period was rated on a six point scale $(0=$ less than one attack per year to $5=$ more than one attack per day). Duration was rated using a similar scale ( $1=$ attacks lasting a few seconds to $5=$ attacks lasting a month or more). The two scores were combined to give a total severity score (for example, $10=$ frequent, prolonged attacks).

The severity of the abnormalities detected on vestibular testing was rated as follows:

1) Canal paresis was measured on a three point scale using the Jongkees formula ${ }^{9}$ ( $0=$ canal paresis less than $8 \%, 1=$ between $8 \%$ and $20 \%$ and $2=$ greater than $20 \%$ ).

2) Spontaneous nystagmus in the dark, with slow component velocity greater than $5 \% / \mathrm{sec}$ ond, was rated on a four point scale using Alexander's law ${ }^{15}(0=$ no nystagmus, $1=$ first degree, $2=$ second degree and $3=$ third degree).

3) Directional preponderance was measured on a three point scale according to Jongkees formula ${ }^{9}(0=$ no directional preponderance, 1 $=$ directional preponderance smaller than $20 \%$ and 3 = greater than $20 \%$ ).

The same neuro-otological tests were performed at the initial and follow up sessions. Psychotropic medication was stopped for at least a week before testing and patients were asked to refrain from drinking alcohol or smoking for the preceding 24 hours.

Changes in vestibular tests between the initial and follow up examinations were rated as follows:

1) Canal paresis: $-1=$ deterioration greater than $10 \%, 0=$ no change and $+1=$ improvement greater than $10 \%$.

2) Spontaneous nystagmus: $-1=$ severity increased by a degree or more, $0=$ no change and $+1=$ decreased by a degree or more.

3) Pattern of abnormalities was thought to have changed if abnormalities in the caloric response had disappeared or if a directional preponderance had developed or disappeared if initially present. Pattern changes were rated as $0=$ no change and $1=$ improvement in the pattern.

An Improvement Index was obtained by adding these three scores.

Differences between the outcome groups were tested using non-parametric tests. Chi square, Mann-Whitney and Kruskal-Wallis one way analysis of variance (ANOVA) were used. $T$ tests were used when appropriate. The statistical package SPSS/PC+ was used for the analysis.

\section{Results}

1) CLINICAL FEATURES AND NEURO-OTOLOGICAL

OUTCOME IN THOSE SEEN AT FOLLOW UP

The average age of the 54 patients seen at follow up was 42.7 years with symptoms first arising at a mean age of 38 (table 1). The duration of their neuro-otological symptoms ranged from four months to ten years (mean 3.7 years) and they had been present from two weeks to eight years (mean 1.4 years) before patients attended the National Hospital. At interview, unsteadiness was the commonest symptom ( $55 \%)$, followed by vertigo (33\%), giddiness $(30 \%)$, lightheadedness $(23 \%)$, tiredness $(20 \%)$, nausea and vomiting (16\%). Less frequent symptoms were headaches, veering to one side, unsteadiness when standing still and positional vertigo. Most patients had 
Table 1 Neuro-otological outcome

\begin{tabular}{lll}
\hline & $\begin{array}{l}\text { Seen at } F U \\
(N=54)\end{array}$ & $\begin{array}{l}\text { Not seen at } F U \\
(N=39)\end{array}$ \\
\hline Age & $42 \cdot 7(18-64)$ & $40 \cdot 0(15-66)$ \\
Group 1 (recovered) & $13(24 \%)$ & $11(28 \%)$ \\
Group 2 (improving) & $28(52 \%)$ & $13(33 \%)$ \\
Group 3 (unchanged/worse) & $13(24 \%)$ & $14(36 \%)$ \\
& & $\star$ \\
\hline
\end{tabular}

*Outcome data missing in one case.

to take time off work (average nine months, range from 0-6 years), a third had to change jobs and $18 \%$ had retired. Nine had to stop driving for up to two years and several others had temporarily stopped playing sports or travelling.

The 54 patients were divided by the neurootologists (LML and RAD), unaware of the psychiatric status, into three outcome groups using the subjective ratings of neuro-otological symptoms. Thirteen patients (24\%) (group 1) had recovered completely, 28 (52\%) (group 2) had partly recovered or were still improving and $13(24 \%)$ (group 3) were unchanged or getting worse (table 1). There were no differences in age, age at onset of symptoms, social class or marital status between the three groups. Rates of recovery were similar for those in the labyrinthine group compared with the rest. Those who recovered or improved had symptoms for an average of two years, whilst those who were unchanged or worse had been ill for twice as long $(p<0.001)$ and took longer to be referred to the National Hospital. Ten out of 26 men had recovered, whilst only three out of 28 women had done so $\left(\chi^{2}=5 \cdot 7, \mathrm{p}=\right.$ $0.06)$.

There were no differences in sex, age of onset, severity and type of symptoms and neuro-otological outcome between those tested at follow up and the rest of the sample (table 1).

2) NEURO-OTOLOGICAL PARAMETERS, SYMPTOMS AND OUTCOME

Patients who presented with typical labyrinthine symptoms (28 out of the initial 93) had more severe canal paresis than the rest (respective means 1.61 and $0.64, p<0.001$ ) and this difference was also present when those tested at follow up were analysed separately. There were no differences in the severity of spontaneous nystagmus or presence of directional preponderance between the two groups. The three symptomatic outcome groups did not differ in the severity of the neuro-otological abnormalities or in their Improvement Index. This index was also similar in those who presented with labyrinthine or with vague symptoms.

3) PSYCHIATRIC MORBIDITY

A) Psychiatric morbidity before the onset of vestibular symptoms

A quarter of the patients $(N=13)$ seen at follow up had experienced psychiatric illness before the onset of vestibular symptoms. The commonest diagnoses, using DSM-III-R terminology, were generalised anxiety disorder $(\mathbf{N}$ $=5)$ and major depression $(\mathrm{N}=4)$ and no cases of panic disorder had occurred. Two patients needed hospital admission and a further two were seen by psychiatrists, the rest were treated by their general practitioners. Eleven of these 13 patients went on to develop psychiatric symptoms later. Although this frequency was similar to that in patients without previous psychiatric illness, these patients tended to remain ill for the whole of the follow up period and to be psychiatric cases at the time of interview.

\section{B) Psychiatric morbidity during the follow up period}

Two thirds of the patients who answered the postal questionnaire $(N=93)$ reported depression and/or anxiety since the onset of the vestibular symptoms and a third had also experienced other psychiatric symptoms. Those seen at follow up $(N=54)$ reported depression more often than the rest, but no such differences were present for anxiety or other psychiatric symptoms.

Thirty seven out of 54 patients interviewed at follow up merit a DSM-III-R diagnosis after the onset of vestibular symptoms. Panic disorder with or without agoraphobia, as a primary or secondary diagnosis, was the commonest $(41 \%)$, in contrast with the diagnoses preceding vestibular symptoms. Major depression occurred in $38 \%$ and dysthymia in $24 \%$. Of the 15 patients with panic disorder, four had previous psychiatric illness, but their earlier symptoms had been different. Two of them had generalised anxiety, one major depression and another a bereavement reaction. In nearly two thirds of the patients psychiatric illness occurred during the first six months of vestibular problems and its duration varied widely. A quarter of patients recovered within six months, whilst half of them had symptoms lasting between one and three years. Half of the patients had seen psychiatrists, but none had been admitted to hospital.

\section{C) Psychiatric morbidity at follow up interview}

Twenty five out of 54 patients (46\%) scored above the cut off point for significant psychiatric morbidity. The presence of psychiatric symptoms was not significantly related to sex, type of presenting symptoms or to the neurootological parameters including the Improvement Index. Psychiatric morbidity was very low $(8 \%)$ in those who were asymptomatic, but equally high $(59 \%)$ in the two groups who were still experiencing symptoms (table 2).

The commonest psychiatric symptoms were insomnia, fatigue, feelings of anxiety and depression and somatic concern. Obsessivecompulsive symptoms, elation or psychotic features were not reported or observed.

The scores of the Beck depression inventory were significantly different in the three groups (table 3), but remained below the generally accepted cut off point for clinically relevant depression $(>11)$. There were no significant differences in the mean state and trait anxiety scores of the three outcome groups, but there was a trend for those with vestibular symptoms 
Table 2 Psychiatric morbidity and neuro-otological outcome

\begin{tabular}{|c|c|c|c|}
\hline & $\begin{array}{l}\text { Group 1 } \\
\text { (Recovered) } \\
(N=13)\end{array}$ & $\begin{array}{l}\text { Group } 2 \\
\text { (Improved) } \\
(N=28)\end{array}$ & $\begin{array}{l}\text { Group } 3 \\
\text { (Unchanged) } \\
(N=13)\end{array}$ \\
\hline $\begin{array}{l}\text { CIS (cases over } \\
\text { cut-off point) } \\
\text { CIS score } \\
\text { Symptom rating } \\
\text { (CIS) }\end{array}$ & $\begin{array}{l}1(8 \%) \\
7 \cdot 3(3 \cdot 9)\end{array}$ & $\begin{array}{l}17(60 \%) \\
15.9(8 \cdot 6)\end{array}$ & $\begin{array}{l}7(54 \%)^{\star \star} \\
15 \cdot 9(7 \cdot 4)^{\star \star}\end{array}$ \\
\hline $\begin{array}{l}\text { Somatic concern } \\
\text { Depression } \\
\text { Depression (rater) } \\
\text { Phobias } \\
\text { Irritability } \\
\text { Fatigue }\end{array}$ & $\begin{array}{l}0.5 \\
0.4 \\
0.5 \\
0.5 \\
0.3 \\
0.6\end{array}$ & $\begin{array}{l}1.0 \\
1.1 \\
1.9 \\
0.8 \\
0.9 \\
1.3\end{array}$ & $\begin{array}{l}1 \cdot 3^{\star} \\
1 \cdot 0^{\star} \\
1 \cdot 7^{\star} \\
1 \cdot 1^{\star} \\
1 \cdot 0^{\star} \\
1 \cdot 2^{\star}\end{array}$ \\
\hline
\end{tabular}

Kruskal-Wallis analysis of variance. ${ }^{\star}<0.05 ;{ }^{\star \star} \mathrm{p}=0.005$. CIS = Clinical interview schedule.

(SD in brackets).

CIS number of cases over cut off point compared using $\chi^{2}$.

to have higher state anxiety scores $(p=0.09)$. The means for the whole group (38.9 and 39.5 respectively) were higher $(p<0.001)$ than the norms reported in the literature $(30.9$ and 34.4 respectively. ${ }^{16}$ The degree of social stress as measured by the SSSI was also significantly greater in those still experiencing neurootological symptoms (table 3 ).

Five patients were experiencing troublesome phobic symptoms at the time of the interview, but over a quarter of the whole sample ( $68 \%$ of those with psychiatric morbidity) had previously done so. Avoidance of crowds, enclosed spaces such as underground trains, buses and cars were common, as were fear of going out alone, heights and the dark. Some patients avoided activities that aggravated their sense of dysequilibrium, such as going into a car wash, looking up at monuments or shiny surfaces or putting garments over their heads. In many cases the feared consequences of these actions (for example, to appear "drunk") had lead to the avoidance of social situations. One patient had, in addition, developed marked anorexic behaviour.

Phobic symptoms were more severe in those with persistent vestibular symptoms. This applied to the total phobic score, ratings of agoraphobia, avoidance of the dark, heights and social situations, but not to other phobias such as fear of blood or animals which should not, a priori, be related to the symptoms of dysequilibrium (table 4).

There were no significant differences in age, sex or duration of vestibular symptoms between those with psychiatric morbidity and the rest. Those with psychiatric morbidity had significantly higher trait anxiety scores and

Table 4 Phobia ratings in the three outcome groups

\begin{tabular}{|c|c|c|c|}
\hline & $\begin{array}{l}\text { Group 1 } \\
\text { (Recovered) } \\
(N=13)\end{array}$ & $\begin{array}{l}\text { Group 2 } \\
\text { (Improved) } \\
(N=28)\end{array}$ & $\begin{array}{l}\text { Group } 3 \\
\text { (Unchanged) } \\
(N=13)\end{array}$ \\
\hline $\begin{array}{l}\text { Total phobia score } \\
\text { Agoraphobia } \\
\text { Social phobia } \\
\text { Falls/heights/dark } \\
\text { Blood/injury } \\
\text { Other phobias }\end{array}$ & $\begin{aligned} 13 \cdot 4(7 \cdot 2) \\
1.8(3 \cdot 1) \\
4 \cdot 2(3 \cdot 8) \\
2.7(3 \cdot 6) \\
7.3(4 \cdot 8) \\
1 \cdot 1(2 \cdot 3)\end{aligned}$ & $\begin{array}{c}25 \cdot 8(15 \cdot 6) \\
5 \cdot 6(6 \cdot 2) \\
11 \cdot 0(8 \cdot 3) \\
5 \cdot 6(4 \cdot 4) \\
10 \cdot 1(8 \cdot 3) \\
2 \cdot 1(3 \cdot 2)\end{array}$ & $\begin{array}{c}31 \cdot 5(17 \cdot 9)^{\star \star} \\
9 \cdot 3(8 \cdot 9) \\
9 \cdot 9(7 \cdot 7)^{\star} \\
8 \cdot 7(5 \cdot 7)^{\star \star} \\
12 \cdot 3(8 \cdot 0) \\
1.9(2 \cdot 6)\end{array}$ \\
\hline
\end{tabular}

Table 3 Depression, anxiety and social stress in the three outcome groups

\begin{tabular}{|c|c|c|c|}
\hline & $\begin{array}{l}\text { Group } 1 \\
(\text { Recovered }) \\
(N=13)\end{array}$ & $\begin{array}{l}\text { Group 2 } \\
\text { (Improved) } \\
(N=28)\end{array}$ & $\begin{array}{l}\text { Group } 3 \\
\text { (Unchanged) } \\
(N=13)\end{array}$ \\
\hline $\begin{array}{l}\text { BDI } \\
\text { STAI-state } \\
\text { STAI-trait } \\
\text { SSSI }\end{array}$ & $\begin{array}{r}3.3(2.8) \\
34.5(7.9) \\
35.6(6.5) \\
4.7(0.9)\end{array}$ & $\begin{array}{c}8 \cdot 0(5 \cdot 2) \\
38 \cdot 8(11 \cdot 7) \\
40.9(9 \cdot 7) \\
3.5(1 \cdot 6)\end{array}$ & $\begin{array}{c}9.7(6.4)^{\star \star} \\
43.5(8.9) \\
40.3(9.7) \\
3.1(2.2)^{\star}\end{array}$ \\
\hline \multicolumn{4}{|c|}{$\begin{array}{l}\text { Kruskal-Wallis analysis of variance. }{ }^{\star}<0.05 ;{ }^{\star} \mathrm{p}=0.01 . \\
\text { BDI = Beck Depression Inventory. } \\
\text { STAI = State-Trait Anxiety Inventory. } \\
\text { SSSI = Social Stress and Support Interview (higher scores less } \\
\text { stress). } \\
\text { (SD in brackets). }\end{array}$} \\
\hline
\end{tabular}

considered themselves to be under greater social stress. There was also a trend for this group to have experienced psychiatric illness more often before the onset of the vestibular symptoms (table 5).

\section{Discussion}

This study did not attempt to look at psychiatric morbidity in specific clinical vestibular syndromes, but to document its relationship to objective peripheral vestibular dysfunction, common to a number of clinical conditions. The use of strict neuro-otological selection criteria and the exclusion of confounding factors such as the use of psychotropic medication are the most important features of our study. The high psychiatric morbidity in our patients agrees with previous reports. ${ }^{1718}$

Factors other than vestibular pathology are at play in determining psychiatric morbidity as no psychiatric illness occurred in a third of our patients. Greater trait and state anxiety and a previous psychiatric history are likely to influence the occurrence and course of psychiatric symptoms. The role of perceived stress is more difficult to determine, as it may be the result of the symptoms rather than their cause.

The discrepancy between the objective evidence of vestibular disturbance and the degree of disability experienced by patients has previously been explained as a result of coexistent psychiatric symptoms. ${ }^{19}$ In our study, the degree of canal paresis was greater in those with typical labyrinthine symptoms, but the severity of the abnormalities in the vestibular tests or their change over time were not significantly related to psychiatric morbidity or to clinical outcome. This lends support to the idea that vestibular pathology may act as a precipitant for psychiatric illness in those at risk and that once the pattern of symptoms is

Table 5 Psychiatric morbidity in symptomatic patient

\begin{tabular}{lcc}
\hline & $\begin{array}{c}\text { CIS cases } \\
(N=24)\end{array}$ & $\begin{array}{c}\text { Non cases } \\
(N=17)\end{array}$ \\
\hline Previous mental illness & 9 & 1 \\
STAI-State & $44.7(11 \cdot 1)$ & $34 \cdot 0(7.5)^{\star \star}$ \\
STAI-Trait & $45.3(8 \cdot 4)$ & $34.3(7 \cdot 1)^{\star \star}$ \\
SSSI & $2.9(1 \cdot 8)$ & $4.0(1 \cdot 8)^{\star}$ \\
\hline Kruskal-Wallis analysis of variance. ${ }^{\star}<0.05 ;{ }^{\star \star} \mathrm{p}=0.005$. \\
STAI = State-Trait Anxiety Inventory. \\
SSSI = Social Stress and Support Interview. (Higher scores less \\
Stress). \\
(SD in brackets).
\end{tabular}


established outcome is largely independent of these abnormalities.

In our study panic disorder and, less frequently, major depression were the commonest diagnoses. Allowing for changes in psychiatric terminology, our findings agree with other reports. ${ }^{12719}$ The occurrence of panic disorder with or without agoraphobia in our patients is unlikely to be a chance finding. Support for a specific link accrues from the fact that these symptoms were only present when psychiatric illness followed vestibular disorder, not vice versa. Similar observations had led Jacob" to postulate a "somatopsychic" explanation for this association. Thus misinterpretation of the physical symptoms of dysequilibrium as presaging catastrophic physical disease could trigger panic attacks in predisposed individuals. The same explanations have been put forwards to account for panic attacks in the context of other altered bodily functions (for example, arrhythmias). ${ }^{21}$ If this hypothesis is correct, the features of the panic attacks and phobias that follow vestibular disorder may be different from those appearing spontaneously or triggered by other somatic pathologies. The homogeneity of symptoms observed in our patients (such as, fear of heights and the dark and avoidance of actions capable of aggravating dysequilibrium) adds some support to this possibility. Similar symptoms are also present in "space" phobias" and in the "motorist disorientation syndrome", disorders attributed to abnormalities in the vestibular apparatus or to central misinterpretation of vestibular information.

Exaggeration and greater variability of responses in caloric tests have been noticed in patients with anxiety neurosis ${ }^{57}$ and markedly suppressed caloric and rotational vestibular responses in the presence of optic fixation have also been reported. ${ }^{6}$ This implies an overactivity of the mechanisms subserving fixation similar to that documented in ballet dancers, aviators and others exposed to repeated angular acceleration who by developing vestibular habituation avoid dysequilibrium. It remains possible that vestibular abnormalities could be secondary to psychological and behavioural factors that exert an effect on attention, arousal or vestibular habituation.

To disentangle the direction of causality neuro-otological studies in patients with strictly defined psychiatric disorders will need to be compared with those, like our own, where the primary selection criteria were the presence of objective vestibular abnormalities. This study does not draw conclusions on how best to treat these patients. Clinical impression suggest that standard vestibular treatments are ineffective unless psychological problems are resolved. ${ }^{22}$ Awareness of the high psychiatric morbidity and appropriate early referral seem judicious steps.

We thank all the patients who took part in the study. Dr Sarah Eagger was supported by the Charter Nightingale Hospital and Dr MA Ron was partly funded by the Scarfe Trust.

1 Pratt RTC, McKenzie W. Anxiety states following vestibular disorders. Lancet 1958;2:347-9.

2 Lilienfeld SO, Jacob RG, Furman JMR. Vestibular dysfunction followed by panic disorder with agoraphobia. $f$ Nerv Ment Dis 1989;177:700-1.

3 Marks IM. Space "phobia": a pseudo-agoraphobic syndrome. F Neurol Neurosurg Psychiatry 1981;44: 387-91.

4 Page NGR, Gresty MA. Motorist's vestibular disorientation syndrome. $f$ Neurol Neurosurg Pyychiatry 1985;48: 729-35.

5 Hallpike CS, Harrison MS, Slater E. Abnormalities of the caloric test results in certain varieties of mental disorder. Acta otolaryngologica (Stockholm) 1951;39:151-9.

6 Dix MR, Hood JD. Vestibular habituation its clinical significance and relationship to vestibular neuronitis. Laryngoscope 1970;80:226-32

7 Jacob RG, Moller MB, Turner SM, Wall C. Otoneurological examination in panic disorder and agoraphobia with panic attacks: A pilot study. Am $f$ Psychiatry 1985; 142:715-9.

8 Fitzgerald G, Hallpike CS. Studies in human vestibular ance of caloric nystagmus resulting from cerebral lesions. ance of caloric nystagm
Brain 1942;65:115-37

9 Jongkees LBW. Uber die Untersuchungs-methoden des Gleichgewichtsorgans. Fortschritte der Hals-Nasen-Ohrenheille. Kaigen: Basel, 1953:1-147.

10 Goldberg DP, Cooper B, Eastwood MR, Kedward HB, Shepherd M. A standardised psychiatric interview for use in community surveys. Br $\mathcal{F}$ Prevent Soc Med 1970; 24:18-23.

11 Beck AT, Ward CH, Mendelson M, Mock J, Erbaugh J. An inventory for measuring depression. Archives of General Psychiatry 1961;4:56-71.

12 Jenkins R, Mann AH, Belsey E. The background, design and use of a short interview to assess social stress and support in research clinical settings. Social Science and Medicine 1981;15:195-203.

13 Marks IM, Mathews AM. Brief standard self-rating for phobic patients. Behaviour Research and Therapy 1979; 17:263-7.

14 Spielberger CD, Gorsuch RL, Luchene R, Vagg PR, Jacobs GA. Manual for State-Trait anxiety inventory. Palo Alto: Consulting Psychology Press, 1983.

15 Luxon LM. Physiology of equilibrium and its application in the giddy patient. In: Wright $D$, ed. Scott Brown's otolaryngology, 5th ed. Vol 1, Basic sciences. London: Butterworth, 1987

16 Knight RG, Waal-Manning HJ, Spears GF. Some norms and reliability data for the State-Trait anxiety inventory and the Zung self-rating depression scale. $\mathrm{Br} \mathcal{f} \mathrm{Clin}$ Psychol 1983;22:245-9.

17 Rigatelli M, Casolari L, Bergamini G, Guidetti G. Psychosomatic study of sixty patients with vertigo. Psychotherapy and Psychosomatics 19841;41:91-9.

18 Levinson HN. A cerebellar-vestibular explanation for fears and phobias: hypothesis and study. Perceptual and Motor and phobias: hypothesis

19 Hallam RS, Stephens SDG. Vestibular disorder and emotional distress. Fournal of Psychosomatic Research 1986; 29:407-13

20 Jacob RG. Panic disorder and the vestibular system. Psychiatric Clinics of North America 1988;11:361-74.

21 Bass C, Kartsounis L, Lelliott P. Hyperventilation and its relationship to anxiety and panic. Integrative Psychiatry 1987;5:274-91.

22 Beyts JP. Vestibular rehabilitation. In: Stephens D, ed. ScottBrown's Otolaringology, Vol 2 5th ed. London: Butterworths, 1987:532-57. 